Makale türü / Article type: Araştırma / Research

\title{
Performans Ölçümünde Süreç Katkı Muhasebesinin Rolü: Örnek Bir Uygulama ${ }^{1}$
}

$* * *$

\section{The Role of Throughput Accounting in Performance Measuring: A Case Study}

\author{
Doç. Dr. Mustafa Saveı \\ Recep Tayyip Erdoğan Üniversitesi, İ̈BF, mustafa.savci@erdogan.edu.tr \\ ORCID: 0000-0002-0794-9804 \\ Doktora Öğrencisi, İmad Balioğlu \\ Recep Tayyip Erdoğan Üniversitesi, İïF, imad_balioglu19@erdogan.edu.tr \\ ORCID: 0000-0002-6701-4728
}

\begin{abstract}
Özet
Son y1llarda rekabetin yoğunlaşması yeni üretim sistemlerindeki gelişmeler işletmelerde performans ölçümünde süreç katkı muhasebesini ön planı çıkarmıştır. Süreç katkı muhasebesi, işletmenin performansını verimli ve etkin bir şekilde ölçerek, darboğazların elimine edilmesine, kaynakların daha etkin kullanılmasına, maliyetlerin azaltılmasına ve kâr maksimizasyona katkı sağlar. Çalışmanın temel amacı, işletmelerin performans ölçümünde süreç katkı muhasebesinin rolünün incelenmesidir. Bunun için kamuya ve özel sektöre ait örnek birer işletmede yarı yapılandırılmış mülakat yöntemi uygulanmıştır. Elde edilen bilgiler karşılaştırılmış ve uygulama sonucunda performans ölçümünde süreç katkı muhasebesinin olumlu etkisi olduğu görülmüştür.
\end{abstract}

Anahtar Kelimeler: Performans Ölçümü, Süreç Katkı Muhasebesi, Faaliyet Ölçütleri, Finansal Ölçütleri, Türev Ölçütleri.

JEL Sınıflandırması: M10, M40, M41

\begin{abstract}
In recent years, the competition has increased in business world to develop new production systems which has led to the emergence of throughput accounting in performance measurement. Throughput accounting contributes to measuring business performance efficiently and effectively by eliminating bottlenecks, using resources more effectively, reducing costs and increasing profits. The purpose of this study is examining the role of throughput accounting in business performance measurements. For this purpose, a semi-structured interview method was applied in a case study which belongs to the public and private sector. The obtained data has been compared and as a result we can say that throughput accounting has positive effects on the performance measurement.
\end{abstract}

Keywords: Performance Measurement, Throughput Accounting, Operational Measurements, Financial Measurements, Derivatives.

JEL Classification: M10, M40, M41

\section{GİRiș}

Performans ölçümü, işletmelerin önceden belirlenen hedeflerine ne ölçüde ulaştığını belirleyen bir işlem dizisidir (Bayrakdaroğlu, A. \& Ege, İ., 2007: 95). Performans ölçümünde kullanılan bazı yöntemler bulunmaktadır. Bu yöntemlerden biri süreç katkı muhasebesidir. Süreç katkı muhasebesi kavramı, 1986 y1lında ABD'de ilk defa olarak ortaya çıkmıştır. Bu kavram, Goldratt ve Cox tarafından modern bir yöntem olarak geliştirilmiştir (Scarlett, 2005: 363). Daha sonra (1988/1989) arası Galloway ve Waldron zamana

\footnotetext{
${ }^{1}$ Bu makale, yazarları tarafindan (17-19 April 2019 Artvin International Congress On Social Sciences (AICOSS 19) Hopa, Artvin / Türkiye) sunulan bildiriden geliştirilmiştir.
} 
dayalı yeni bir maliyetlendirme yöntemi geliştirerek bu yöntemi süreç katkı muhasebesi olarak adlandırmışlardır (Neely, Gregory \& Platts, 2005: 1233).

Süreç katkı muhasebesine göre işletme kaynaklarının etkin kullanabilmesi için kısıtların doğru tespit edilmesi ve bu kısıtların ortadan kaldırılarak işletme darboğazlarının elimine edilmesi gerekir (Salafatinos, 1995: 58). İşletmedeki darboğazların elimine edilmesi, işletmenin daha verimli çalışmasını sağlayarak, kâr maksimizasyonu olumlu etkiler (Savcı \& Balioğlu, 2019: 190). Bu olumlu etki yönetimin karar alma süreçlerine destek sunabilir (Scarlett, 2005: 363). Aynı zamanda, süreç katk1 muhasebesi işletme faaliyetleri arasında eşgüdüm sağlayarak üretim maliyetlerinin planlanıp kontrol edilmesine ve performansın ölçülenmesine katkı sağlayabilir.

İşletme performansının ölçülebilmesi için süreç katk1 muhasebesinde faaliyet ölçütlerine, finansal ölçütlerine ve türev ölçütlerine özen göstermek gerekir (Savcı \& Balioğlu, 2019: 194).

\section{LITERATÜR ÇALIŞMALAR}

Literatürde süreç katkı muhasebesi, birçok çalışmaya konu olmuştur. Bu konu ile yapılan bazı çalışmaları uluslararası ve ulusal olarak aşağıdaki gibi sıralamak mümkündür.

\subsection{Uluslararası Çalışmalar}

Hua, (2014) Çalışmasında, Fiyatlandırma politikalarının geliştirilmesinde süreç katkı muhasebesinin rolünü örnek bir işletmede incelemiştir. Bu çalışmada geleneksel maliyet hesaplama yöntemleri ile süreç katk1 muhasebesi arasındaki farklılıklardan söz etmiştir. Süreç katkı muhasebesinin örnek işletmede fiyatlandırma stratejisi ile mevcut kapasiteyi ve kâr seviyesini artırdığı sonucuna varmıştır.

Huang, (2013) Çalışmasında, İşletmenin sipariş stratejisinin geliştirilmesinde süreç katkı muhasebesinin rolünü üretim işletmelerinde örnek bir uygulama ile incelemiştir. Çalışma sonucunda uygun maliyet-kâr modeli önermiş, işletmenin sipariş stratejisi geliştirmesi için kısa vadeli fiyatlandırma ve uzun vadeli brüt kâr stratejisine odaklanılması gerektiği vurgulanmıştır.

Yao, (2011) Çalışmasında, karma ürünlerde kârın maksimize edilmesinde süreç katkı muhasebesinin etkisini incelemiştir. Çalışma sonucunda süreç katk1 muhasebesinin; işletmenin üreteceği en uygun ürünlerinin belirlenmesinde, işletme kârının en üst seviyeye çıkarılmasında, yöneticilerin verecekleri kararlara yardımcı olabileceği tespit edilmiştir.

Chen, (2007) Çalışmasında, süreç katkı muhasebesinin etkisini örnek bir endüstri işletmesinde incelemiştir. Çalışma sonucunda işletmedeki sorunların kaldırılması ve yönetim muhasebesinin geliştirilmesi için süreç katkı muhasebesinin kullanılmasının gerekliliği vurgulanmıştır.

Hanqi, (2006) Çalışmasında, karar destek sisteminin geliştirilmesinde süreç katkı muhasebesinin rolünü incelemiştir. İşletmenin vereceği kararı geliştirebilmesinde süreç katkı muhasebesi temelli karar destek sistemi modelini önermiştir. Süreç katkı muhasebesi ile işletmenin karar destek sisteminin daha güçlü olduğuna vurgu yapmıştır.

\subsection{Ulusal Çalıșmalar}

Akkaş, (2016) Çalışmasında, süreç katkı muhasebesinin yönetim muhasebesi aracı olarak kullanımının; işletme kârlılığı, yatırım ve finans kararlarını nasıl etkilediğini bir üretim işletmesinde incelemiştir. Çalışmada işletmenin bulunan kısıttan habersiz olmasının üretim kapasitesini etkili kullanmasına engel olduğuna işaret edilerek, süreç katkı muhasebesinin geleneksel yöntemlere göre üretilen ürünlerin birim başına kârı artırdığını vurgulanmıştır. 
Ferdiş, (2010) Çalışmasında, süreç katkı muhasebesinin bir üretim işletmesinde işletme kârına nasıl etki yaptığını geleneksel yöntemlerle karşılaştırmıştır. Karşılaştırmada, süreç zamanı, ürünlerin satış fiyatı, kısıtların maliyeti dikkate alınmıştır. Bu üç faktörün kârı etkilediği görülmüştür.

Demirel Utku, (2007) Çalışmasında en uygun ürün karmasının belirlenmesinde süreç katkı muhasebesi ile geleneksel yöntemlerden tam ve değişken maliyet yönteminin kârlılığa etkisini incelemiştir. Çalışmada ürün karması belirlenmesinde belirtilen bu üç maliyet yöntemi karşılaştırılarak ürün karmasının işletme kârını nasıl etkilediği ortaya konulmuştur.

\section{SÜREÇ KATKI MUHASEBESI}

Süreç katkı muhasebesi, 1975 yılından sonra maliyet ve yönetim muhasebesiyle ilgili modern maliyetleme yöntemleri ve endüstriyel gelişmelere bağlı olarak 1986 yılında ortaya çıkmıştır. Bu süreçle ilgili gelişim aşağıda şekil 1'de gösterilmiştir (Hutchinson, 2007: 27).

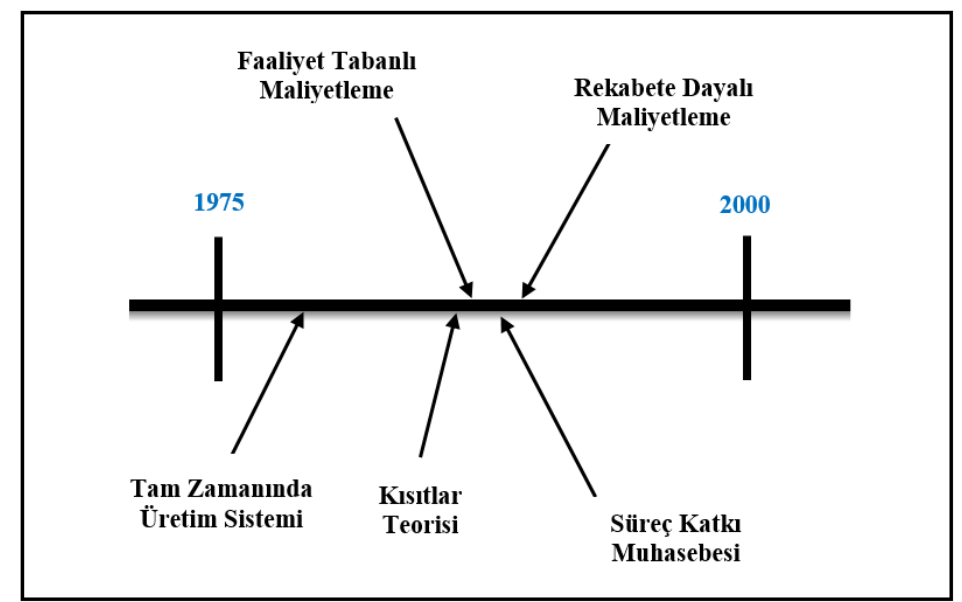

Şekil 1. Süreç Katk1 Muhasebesinin Gelişimi.

Yönetim muhasebesinde, süreç katkı muhasebesinin en büyük rolü, planlama ve kontrol işlemleridir. Süreç katkı muhasebesinde, maliyet sonuçları ve raporlar kısıtlar teorisi ilkelerine dayanmaktadır (Yurevich, Vasilevna \& Anatolyevna, 2018: 307). Süreç katkı muhasebesinin temel gelişme noktaları aşağıdaki gibi siralanabilir:

Tablo 1. Süreç Katkı Muhasebesinin Temel Gelişme Noktaları:

\begin{tabular}{ll}
\hline Kriterler & Süreç katkı muhasebesi \\
\hline Yöntem Olarak Ortaya Çıkışı & 1988. \\
Yöntemin Ana Geliştiricileri & Goldratt, E. \& Galloway, D. \& Valdron, D \& Corbett, T. \& Bragg: \& Dagdeil, D. \\
Yöntemin Ana Görevi & \& Jones, T. \& Norin, E. \& Smith, D. \& Noreen, E. \& Mackey, J. T. \\
Odaklandığı Konu & Süreç katkı değerinin artırılması. \\
Maliyet Değişikliklerin Etkisi & Ürünler. \\
Maliyetlerin Sınıflandırılması & Üretim ve faaliyet giderlerine. \\
Maliyet Dağıtımı & Toplam değişken maliyetler. \\
Maliyetin Belirlenmesi & Kullanılmaz. \\
Maliyet Hesapları & Değişken maliyetler üzerinden tahmin edilir. \\
İşletmenin Verimlilik Ölçütleri & Yönetim muhasebesi hesapları kullanılır: toplam değişken maliyetler, faaliyet \\
Ana Faaliyet Göstergeleri & giderleri ve süreç katkı. \\
Yönetim Kararları & Finansal ve finansal olmayan ölçütler. \\
\hline
\end{tabular}

(Kaynak: Elsukova, 2015: 84-85) 
Süreç katkı muhasebesi, finansal ve finansal olmayan ölçütler oluşturarak üretim faaliyetlerinde en iyi akış1 ve en uygun zamanı göstermek için değişken maliyetlerin tahmin edilmesine odaklanır. Bu durum aynı zamanda planlama, kontrol, analiz ve karar verme faaliyetlerini kolaylaştırır (Elsukova, 2015: 85).

\subsection{Süreç Katkı Muhasebesinin Tanımı ve Amacı}

Süreç katkı muhasebesi, üretim ve faaliyet giderlerini süreç ile ilişkilendiren bir performans ölçümü yöntemi olarak tanımlanabilir (Tanış, 1998: 4). Süreç katkı muhasebesi bir başka tanımda ise; işletmenin darboğaz faaliyetlerini kaldırarak, işletme bölümlerini geliştiren ve en yüksek getiri elde etmeye odaklanan bir maliyet ve yönetim muhasebesi yöntemi olarak tanımlanmıştır (ICAI, 2016: 21).

Süreç katkı muhasebesinin genel uygulama alanı üretim faaliyeti ve tedarik zinciridir. (Parkhi, Tamraparni \& Punjabi, 2015: 1). Buna rağmen süreç katkı muhasebesinin amacı ile tam zamanında üretim siteminin amacı benzerlik göstermektedir. Bu benzerlik, özellikle üretim süreçlerinde faydalı olmayan unsurların ortadan kaldırılması, üretim ve teslim süresinin azaltılmasında ön plana çıkar (Scarlett, 2005: 368).

Süreç katkı muhasebesinin amacı, işletmenin üretim faaliyetleriyle ilgili zaman planlamasını her aşamada yaparak süreç katkı değerini maksimize etmektir (Scarlett, 2005: 547). Bu amaca ulaşabilmek için aşağıda belirtilen noktalara odaklanılmas1 gerekmektedir. Bunlar (Scarlett, 2005: 547):

- İşletmedeki darboğazların kaldırılması,

- Üretim sistemindeki etkinliğin en üst düzeye artırılması,

- Optimum ürün karışımının üretilmesidir.

Bunun yanında, süreç katkı muhasebesinden beklenen amaçlara ulaşabilmek için üretim hızı ve üretim kısıtları göz önünde bulundurulmalı ve arzulanan üretime en kısa zamanda ulaşılmalıdır (ICAI, 2016: 21). Bunun için, işletmenin tedarik zincirinin en uygun halde getirilmesi gerekmektedir (Lin, Tasi, Li, Tsai, Lu, \& Ho, 2013: 5).

Süreç katkı muhasebesinde işletmenin başarısını sağlamak için beş faktör dikkate alınmalıdır. Bu faktörler: (1) kısıtlar, (2) kapasite, (3) zaman, (4) nakit akımı ve (5) süreç katkıdır (Bayazıtlı, Gürel \& Yayla, 2005: 197-198). İşletmenin başarıya ulaşabilmesi için bu faktörlerle ilişkili aşağıda belirtilenlerin yapılması gerekir.

- Tüm kısitların ortadan kaldırılması,

- Dar boğazlara sebep olabilen kapasite sorunlarının ortadan kaldırılarak işletmenin arz ve talep dengesinin iyi belirlenmesi,

- Üretim sürecindeki gerekli olan malzemelerin gerektiği miktar ve zamanda bulundurularak stok seviyesinin en aza düşürülmesi,

- İşletmenin sabit yüklerini karşılayacak nakit olanaklara odaklanması,

- Kârlılığının ve satışlarının arttırılması, direkt ilk madde ve malzeme giderlerinin ve tüm faaliyet giderlerinin azaltılmasi gerekir.

\subsection{Süreç Katkı Muhasebesinin Felsefesi ve Temel İlkeleri}

Süreç katkı muhasebesi ilk çıktığı zamanlarda modern bir yönetim felsefesi olarak düşünülse de sonraları bu felsefenin muhasebeye de uygulanabileceği görülmüştür (Tanış, 1998: 189). Süreç katkı muhasebesinde, direkt ilk madde ve malzeme giderleri tek değişken gider kabul edilmiş, bu giderin dişındaki tüm giderler (direkt işçilik, genel üretim giderleri) faaliyet giderleri olarak dikkate alınmış ve bu giderler sabit gider olarak kabul edilmiştir (Dugdale \& Jones, 1996: 25).

Süreç katkı muhasebesinin felsefesinde üç önemli nokta vardır. Bunlar aşağıdaki gibi açıklanabilir: 
- Süreç katkı muhasebesinde, öncelikle üretim sürecine odaklanılarak süreç katk1, faaliyet giderleri ve yatırım getirisinin dikkate alınması gerekmektedir. Çünkü, bunlar üretim analizi, kâr planlama ve işletmenin başarılı olmasını kolaylaştırır (Myrelid, 2013: 23).

- Süreç katk1 muhasebesinde üretim faaliyetleriyle ilgili zaman planlaması yapılarak müşteri siparişlerinin tam zamanında teslim edilmesi sağlanarak işletmenin nakit akım sürecinin optimizasyonu çalışılmalıdır (Walker, 2002: 13-14). Bu durum aynı zamanda, üretim planlaması ve türev ölçütlerinden süreç etkinliğinde de önemlidir (Dražıć Lutılsky, Liovıć \& Markovıć, 2018: 1387).

- Süreç katkı muhasebesinde, üretim göstergelerinin senkronizasyonunun artırılması için süreç katk1, stok ve faaliyet giderlerine odaklanılması gerekmektedir (Anwarul Islam, 2015: 19-20).

Süreç katkı muhasebesinin temel ilkeleri aşağıdaki gibi sıralanabilir (Elsukova, 2015: 84):

1) Ürünlerin satış değeri artırılmalıdır.

2) Süreç katkı değeri en üst düzeye çıkartılmalıdır.

3) İşletmenin faaliyetleri hızlı olmalıdır.

4) Ürün maliyetleri karşılaştırılabilmelidir.

5) İşletme bölümlerinde bütünlük ve entegrasyon olmalıdır.

6) Muhasebe ve analiz teknikleri mükemmel olmalıdır.

\section{SÜREÇ KATKI MUHASEBESİ VE PERFORMANS ÖLÇÜTLERİ}

Süreç katkı muhasebesi, işletmelerde her alt birimin, birbirinden bağımsız olarak verimliliklerini en üst düzeye çıkarmak yerine işletmenin toplam performansını optimize etmeye çalışmaktadır (Bayazıtlı vd., 2005: 202).

\subsection{Performans Ölçütleri}

İşletmelerde, karar destek sisteminin geliştirilmesi, bölümlerin değerlendirilmesi ve toplam performansın optimize edilmesi süreç katkı muhasebesinde performans ölçütlerinin kullanılmasını gerektirmektedir (Kaygusuz, 2011: 177). Performans ölçütlerin verimli ve etkin bir şekilde kullanılması; işletme faaliyetlerin optimum olmasına, yapılan hataların ve kısıtların ortadan kaldırılmasına katkı sağlar (Lin vd., 2013: 5).

Performans ölçütleri süreç katkı muhasebesinde faaliyet ölçütleri, finansal ölçütleri ve türev ölçütlerinden oluşmaktadır. Bunlar aşağıdaki şekil 2'de gösterilmiştir (Majerčák, Cisko \& Majerčáková, 2013: 897):

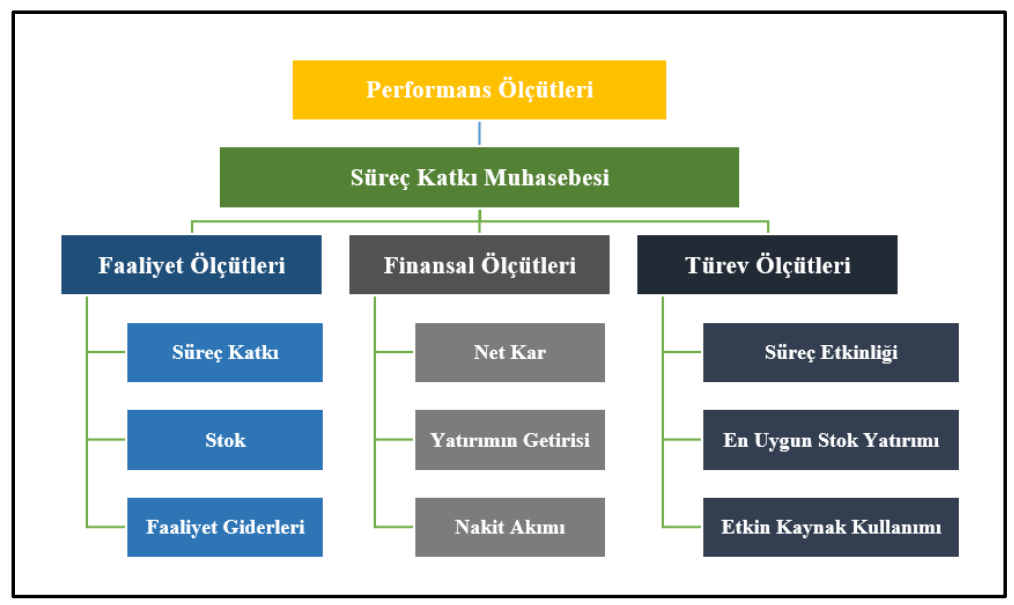

Şekil 2. Süreç Katkı Muhasebesi ve Performans Ölçütleri.

\subsubsection{Faaliyet Ölçütleri}

Faaliyet ölçütleri, üretim faaliyetlerinin verimliliğini ve kârlılığını doğru bir şekilde değerlendirir. Bu ölçütler aynı zamanda işletmeye ne kadar para yatırıldığını, işletmenin ne kadar para tutması gerektiğini ve 
işletmenin faaliyetlerini gerçekleştirebilmek için ne kadar para harcaması gerekeceği soruların cevaplanmasını sağlar. Bu durum işletmelerde üretim faaliyetleri için doğru kararlar vermeyi sağlayan prosedürlerin oluşturulmasında önemli bir rol oynar (Ünal, 2000: 21).

Faaliyet ölçütleri ile ilgili üretim faaliyetleri için herhangi bir karar vermeden önce üç soruya cevap aranması gerekmektedir. Bu sorular aşağıdaki gibi sıralanabilir (Goldratt, 1990: 19):

- İşletmenin kazançları ne kadardır?

- İşletmenin toplam stok tutarı ne kadardır?

- İşletmenin bu döneme ait faaliyet giderleri ne kadardır?

Süreç katkı muhasebesinde faaliyet ölçütleri; süreç katkı, stok ve faaliyet giderlerinden oluşmaktadır (Chase, Aquılano \& Jacobs, 1998: 793-794). Bu faaliyet ölçütleri aşağıdaki gibi açıklanabilir:

\subsubsection{Süreç Katkı}

Süreç katkı muhasebesinde süreç katkı ölçütü en önemli faaliyet ölçütlerinden biridir. Süreç katkı, satışlar yoluyla elde edilen kazançların tümüdür (Lin vd., 2013: 5). Süreç katkı ölçütünde satışların değeri önemlidir. Çünkü, beklenen faydanın maksimizasyonunun sağlanması, işletmenin tüm ürünlerinin satılmasını ve satış değerinin artırılmasını gerektirmektedir (Lin vd., 2013: 5). Süreç katkı, kâr amaçlı işletmelerde; satış hacminden ilk madde ve malzeme maliyetlerinin çıkartılması yoluyla hesaplanabilmektedir (Chase vd., 1998: 793-794). Kâr amaçsız işletmelerde ise; işletmenin müşterilere sunduğu hizmet miktarı olarak belirlenebilmektedir (Demirel Utku, 2007: 33).

\subsubsection{Stok}

Stok, işletmenin satmak ve üretmek amacıyla satın aldığı iktisadi varlıklara yatırdığı değer kullanımlarını ifade eder (Chase vd., 1998: 793-794). Bu değer kullanımı, satışlara yönelik olarak yapılan yatırımların tümüdür (Lin vd., 2013: 5). Süreç katk1 muhasebesinde stok değerine isçilik ve genel üretim giderleri eklenmez (Mokabel, 2016: 71). Süreç katkı muhasebesinde daha fazla stok bulundurarak işletmenin belirtilen amaçlarına ulaşılamaz.

\subsection{3 Faaliyet Giderleri}

Faaliyet giderleri, direkt ilk madde ve malzeme giderleri dışındaki tüm giderlerdir (Chase vd., 1998: 793794). Bu giderler, isçilik giderleri, genel üretim giderleri, pazarlama, satış ve dağıtım giderleri, genel yönetim giderleri ve benzeri giderleri kapsamaktadır.

Özet bir ifade ile, faaliyet ölçütleri üzerinden işletmenin performansını artırmak için, sürecin etkinliği artırmalı, stok ve faaliyet giderleri azaltılmalıdır (Savcı \& Balioğlu, 2019: 193).

\subsubsection{Finansal Ölçütleri}

Finansal ölçütleri, işletmenin finansal başarısını ölçmeye yarar. Bu ölçütler özellikle işletmenin kârlılık amacını değerlendirmede daha anlamlı ve doğru sonuçlar elde edebilmek için önemlidir (Ünal, 2000: 19). Finansal ölçütleri üç tanedir. Bunlar: net kâr, yatırımın getirisi ve nakit akımı olarak sıralanabilir (Chase vd., 1998: 793-794):

\subsubsection{Net Kâr}

Net kâr, süreç katkı değerinden toplam faaliyet giderlerinin çıkartılması şeklinde ifade edilmektedir (Demirel Utku, 2007: 34). Süreç katkı muhasebesinde, işletmenin temel amacı bugün ve gelecekte net kâr elde etmek ve bu kârı arttırmaktır (Corbett, 1998: 28-29). Fakat, işletmenin net kârının arttırılması tek başına bir anlamı yoktur. Çünkü, süreç katkı muhasebesinde işletmenin kazandığı paranın yeterli olup olmadığını değerlendirmek için net kârın dışında diğer finansal ölçütlere ihtiyaç vardır (Demirel Utku, 2007: 34). 


\subsubsection{Yatırımın Getirisi}

İşletmenin elde ettiği kârın yüksek ve yeterli olup olmadığını değerlendirmede, net kâr tek başına yeterli bir ölçüt olmadığından yatırımın getirisi ölçütüne ihtiyaç vardır (Demirel Utku, 2007: 34). Yatırımın getirisi, süreç katkı değerinden faaliyet giderlerinin çıkartılıp bulunan değerin iktisadi varlıklara yatırdığı değere (yatırımlara) bölünmesidir (Chase vd., 1998: 793-794).

\subsubsection{Nakit Akımı}

Nakit akımı, finansal yükümlülüklerin karşılanabilmesi için mevcut olan para miktarıdır (Demirel Utku, 2007: 34). Süreç katkı muhasebesinde finansal ölçütlerde nakit akım tablosu önemlidir. Çünkü, nakit akım tablosu işletmelerin nakit akımlarının kaynak ve kullanımı hakkında bilgi sunar. İşletmenin finansal durumu hakkında değerlendirme yaparak gelecekteki nakit akımı hakkında tahmin yapılmasını kolaylaştırır. Bu sayede, planlama ve karar verme sürecinde etkinlik sağlanabilir (Tüfekçi \& Karaca, 2019: 157-158).

Özet bir ifade ile, finansal ölçütleri üzerinden performansı artırmak için, en uygun nakit akımı sağlanmalı, faaliyet giderleri azaltılmalı ve hedeflenen yatırım getirisine ulaşılmalıdır (Savcı \& Balioğlu, 2019: 193).

\subsubsection{Türev Ölçütleri}

Türev ölçütleri, işletmede savurganlıkların ortadan kaldırılmasını, kaynakların etkin kullanılmasını ve stoklara en uygun yatırım yapılmasını sağlayan bir ölçüttür. Bu ölçüt, süreç etkinliği, en uygun stok yatırımı ve etkin kaynak kullanımından oluşmaktadır (Majerčák vd., 2013: 897). Bunlar aşağıdaki gibi sıralanabilir:

\subsubsection{Süreç Etkinliği}

Süreç etkinliği müşteri siparişlerinin tam zamanında eksiksiz olarak karşılanıp karşılanmadığını inceler (Lin vd., 2013: 5). Bu sayede tedarik zincirinin süreç çıtılları değerlendirilir (Gupta \& Andersen, 2018: 4659). Çünkü, süreç etkinliği aynı zamanda tedarik zincirinin güvenilirliğinin bir ölçütüdür (Cox III, Boyd, Sullivan, Reid, \& Cartier, 2012: 121). Süreç etkinliğinde tüm siparişler tam zamanında karşılanmalı ve siparişlerdeki gecikmelere firsat verilmemelidir.

\subsubsection{En Uygun Stok Yatırımı}

En uygun stok yatırımı, üretim sürecinin etkinliğinin bir ölçütüdür (Cox III vd., 2012: 48). Süreç katk1 muhasebesinde en uygun stok yatırımı, üretimi kesintisiz sürdürmek ve stoklara gereğinden fazla para bağlanmamasıyla ilgilidir. Bu ölçüt, siparişlerin erken ya da geç olmaması için tasarlanmıştır (IMA, 1999: 24). Başka bir ifade ile, en uygun stok yatırımı, işletmenin gereksiz kaynak kullanmasını engelleyerek hem üretim zamanında gerçekleşmesini hem de müşteri memnuniyetini sağlayacaktır.

\subsection{3..3. Etkin Kaynak Kullanımı}

Etkin kaynak kullanımı ölçütü, işletmenin gereğinden fazla yapılan faaliyet giderlerini belirlemek için tasarlanmıştır. Bu ölçüt, işletmenin gereksiz yatırım yapmamasına odaklanarak etkin olmayan kaynak kullanımına izin vermez. Etkin kaynak kullanımı, aynı zamanda en uygun stok yatırımı ile de ilgilidir (Ricketts, 2007: 210).

Özet bir ifade ile, türev ölçütleri üzerinden işletmenin performansını artırmak için; süreç etkinliği, en uygun stok yatırımı ve etkin kaynak kullanımı sağlanmalıdır (Savcı \& Balioğlu, 2019: 194).

\section{ISSLETMELERIN PERFORMANS ÖLÇÜMÜNDE SÜREÇ KATKI MUHASEBESINIIN ROLÜ VE BİR UYGULAMA}

Bu bölümde uygulamanın amacı ve kapsamı, metodolojisi, kısıtları ve bulguları ile ilgili bilgiler verilmiştir. 


\subsection{Uygulamanın Amacı ve Kapsamı}

İşletme faaliyetlerine dair para cinsinden ölçümlerde ortaya çıkabilecek sapmaların işletmelerin geleceğe dair hatalı kararlara yol açması beklenir. İşletmelerde verilecek bu türden hatalı kararların işletmeye maliyeti öngörülenden yüksek olabilir. Bu nedenle, işletmelerin hem varlıklarını sürdürebilmeleri hem de rekabet üstünlüğü sağlayabilmelerinde süreç katkı muhasebesi olgusu önemli bir nitelik kazanmıştır. Süreç katkı muhasebesinde önemli konularından biri de performans ölçümüdür. Bunun için, faaliyet ölçütlerine, finansal ölçütlerine ve türev ölçütlerine özen göstermek gerekir. Çünkü süreç katkı muhasebesinin temel amac1, stok ve faaliyet giderlerini azaltarak işletmede sürekli iyileştirme ve geliştirme sürecini gerçekleştirmektir.

Bu uygulamanın amacı, kuru çay üreten aynı kapasiteye sahip kamuya ve özel sektöre ait birer işletmede performans ölçümünde süreç katkı muhasebesinin etkisini değerlendirmektir. Çalışma kapsamına çay sektörüne ait işletmelerin alınmasının nedeni, bu sektörün bölge ve Türkiye ekonomisi için önem arz etmesidir.

\subsection{Uygulamanın Metodolojisi}

Uygulamada kamuya ve özel sektöre ait birer çay işletmesinde yarı yapılandırılmış mülakat yöntemi kullanılmıştır. Uygulamada ilgili işletmelerin yöneticileri ile görüşülmüştür. Her bir katılımcıya aşağıda belirtilen sorular sorulmuştur:

1. Rekabetin yoğunlaşması ve üretim sistemlerindeki gelişmeler işletmelerde performans ölçümünde süreç katkı muhasebesini ön planı çıkarmıştır. Siz bu konuda ne düşünüyorsunuz?

2. Süreç katkı muhasebesini işletmedeki performans ölçümünde nasıl kullanırsınız?

3. Süreç katkı muhasebesinin, sürecin etkinliğine, stoklarına ve faaliyet giderlerine etkisi hakkında ne düşünürsünüz?

4. Süreç katkı muhasebesinin aşağıda sıralanan ölçütlerinden hangisi işletmenizde daha önemlidir?

- Faaliyet ölçütleri (süreç katkıs1- stok- faaliyet giderleri).

- Finansal ölçütleri (net kâr- yatırımın getirisi- nakit akımı).

- Türev ölçütleri (süreç etkinliği- en uygun stok yatırımı- etkin kaynak kullanımı).

5. Size göre süreç katkı muhasebesinin en önemli faydaları nelerdir? Bu faydalardan üç tanesini önem sirasına göre nasıl siralarsinız?

Görüşmede, yukarıda sorulan sorulara cevap aranmış ve performans ölçümünde süreç katkı muhasebesinin rolü hakkında gerekli bilgilere ulaşma imkânı elde edilmiştir.

\subsection{Uygulamanın Kisitları}

Uygulamanın kısıtı olarak gerçekleştirilen yarı yapılandırılmış mülakat yönteminin kalitatif bir araştırma olması sebebiyle elde edilen sonuçların sektördeki tüm işletmeler için genelleme yapılamayacağı, sadece ilgili duruma ilişkin fikir vermesi yönünde önem arz ettiği söylenebilir.

Uygulamanın diğer bir kısıtı, bölgede kamuya ve özel sektöre ait çok sayıda fabrika olmasına rağmen birer fabrikanın incelenmesi ve yarı yapılandırılmış mülakatın yalnızca işletme yöneticilerine yapılmasıdır.

\subsection{Uygulamanın Bulguları}

Uygulama sonucunda, işletmelerin performans ölçümünde süreç katkı muhasebesinin olumlu etkisi olduğu görülmüştür. Elde edilen bilgilerden kamuya ve özel sektöre ait çay işletmesi arasında önemli bir farklılık görülmemiştir. Sorulan bu sorular karşıllı̆ında alınan cevapların genel olarak değerlenmesi yapılmış önce kamu sektör işletmesi sonra özel sektör işletmesi olarak aşağıda belirtilmiştir.

1. Her iki işletmede performans ölçümünde süreç katkı muhasebesini önemli bulmuşlardır. Bu önemin, özellikle satışların artması ve süreç katkı değerinin analiz edilmesinde etkili olduğunu belirtmişlerdir. 
2. Kamu sektör işletmesi yöneticileri, performans ölçümünde süreç katkı muhasebesinin doğru karar vermede kullanıldığını ifade etmişlerdir. Buna karşılık, özel sektör işletmesi yöneticileri ise darboğazların elimine edilmesinde kullanıldığına işaret etmişlerdir.

3. Her iki işletmede süreç katkı muhasebesi sayesinde faaliyet giderlerine ve uygun üretim miktarına odaklanarak sürecin etkinliğinin sağlandığı ve faaliyet giderlerinin azaltıldığını ifade etmişlerdir.

4. Kamu sektör işletmesi yöneticileri, performans ölçütlerinin önem sırasını birinci sırada \%48 ile faaliyet ölçütleri, ikinci sırada \%33 ile finansal ölçütleri, üçüncü sırada \%19 ile türev ölçütleri sıralanmışlardır. Buna karşılık, özel sektör işletmesi yöneticileri ise, birinci sırada \%42,86 ile finansal ölçütleri, ikinci sırada \%28,57 ile faaliyet ölçütleri, üçüncü sırada \%28,57 ile türev ölçütleri olarak sıralamıştır.

5. Her iki işletmede süreç katkı muhasebesinin faydalarını aşağıdaki gibi sıralamıştır:

- İşletmenin süreç etkinliğinin ve verimliliğinin artırılması.

- İşletmenin tüm giderlerinin azaltılması.

- İşletmenin sürekli iyileştirilmesidir.

\section{SONUÇ}

Süreç katk1 muhasebesi, işletmede belirlenen hedefe ulaşmada karşılaşılan engelleri azaltarak işletmede sürekli gelişme sağlayan, kaynakların etkin kullanımına ve giderlerin azaltılmasına odaklanan, kâr elde etme amacına hizmet eden performans ölçüm aracı olarak ifade edilebilir. İşletmede performans ölçümünün yapabilmesi için faaliyet, finansal ve türev ölçütlerine odaklanılması gerekir.

$\mathrm{Bu}$ çalışma kapsamında yapılan uygulama sonucunda, işletmenin performans ölçümünde süreç katkı muhasebesinin olumlu etkisi olduğu görülmüştür. Elde edilen bilgilerden kamu ve özel sektöre ait işletmeler arasında önemli bir farklılık görülmemiştir. Fakat, kamu sektör işletmesinde, performans ölçütlerinden faaliyet ölçütleri daha önemli bulunurken; buna karşılık, özel sektör işletmesinde, performans ölçütlerinden finansal ölçütleri daha önemli bulunmuştur. Bunun nedeni olarak, kamu işletmesinde sosyal faydanın daha fazla önemsendiği söylenebilir.

Süreç katkı muhasebesinin genel uygulama alanı üretim faaliyeti ve tedarik zinciri olmasına rağmen özellikle üretim maliyetlerinin önemli bir kısmı direkt ilk madde ve malzeme giderinden oluşan işletmelerde önemli faydalar sağlayabilir. $\mathrm{Bu}$ faydalar, ürün fiyatlandırma politikalarında, sipariş stratejilerinde, en uygun üretim politikalarının belirlenmesinde katkı sağlayarak işletmede maliyet azaltılmasında ve kârın maksimize edilmesinde daha etkili olabilir.

\section{KAYNAKÇA}

Akkaş: (2016). Kısıtlar Teorisi Temelli Süreç Katkı Muhasebesinin Yönetim Muhasebesi Aracı Olarak Kullanımı ve Bir İmalat İsletmesinde Uygulama (Yüksek Lisans Tezi) Başkent Üniversitesi.

Anwarul Islam, K. M. (2015). Throughput Accounting: A Case Study. International Journal of Finance and Banking Research, 1(2), 19-23. http://www.sciencepublishinggroup.com/j/ijfbr Adresinden Alınd1

Bayazıtlı, E. \& Gürel, E. \& Yayla, H. E. (2005). Yönetim Muhasebesinde Güncel Bir Yaklaşım: Dönüşüm Muhasebesi. Türkiye Muhasebe Ĕ̈itimi Sempozyumu (XXIV), 191-221.

Bayrakdaroğlu, A. \& Ege, İ. (2007). Performans Ölçümünde Alternatif Bir Yöntem, Yatırımın Nakit Kârlılığ1 (CFROI) ve Halka Açık Turizm Şirketleri Üzerine Bir Uygulama. Anadolu İşletmecilik Kongresi (VI.), 94108.

Chase, R. B. \& Aquilano, N. J. \& Jacobs, F. R. (1998). Production and Operations Management: Manufacturing and Services (Eighth b.). (F. R. JACOBS, Dü.) Irwin, McGraw-Hill Inc.

Chen, Ch. Ch. (2007). The Application of TFT-LCD Industry by TOC Throughput Accounting. National Chiao Tung University, master's degree. Taiwan. https://hdl.handle.net/11296/c439px Adresinden Alındı

Corbett, Th. (1998). Throughput Accounting. The North River Press. 
Cox III, J. F. \& Boyd, L. H. \& Sullivan, T. T. \& Reid, R. A. \& Cartier, B. (2012). Theory Of Constraints International Certification Organization - The Tocico Dictionary. USA: (C) TOCICO.

Demirel Utku, B. (2007). Kısıtlar Teorisine Dayalı Süreç Katkı Muhasebesinin Muhasebe Yöntemleri İle Karşılaştırılarak Değerlendirilmesi: Bir Örnek Olay Çalışması. Akdeniz Üniversitesi, Doktora Tezi. Antalya, Türkiye.

Dražić Lutilsky, I. \& Liović, D. \& Marković, M. (2018). Throughput Accounting: Profit-Focused Cost Accounting Method. Interdisciplinary Management Research (XIV), 1382-1395.

Dugdale, D. \& Jones, C. (1996). Accounting for Throughput. Management Accounting Jornal, 74.

Elsukova, T. V. (2015). Lean Accounting and Throughput Accounting: An Integrated Approach. Mediterranean Journal of Social Sciences, 6(3), 83-87.

Ferdiş, H. . (2010). Süreç Katkı Muhasebesi ve Bir Üretim Işsletmesinde Uygulama. Yüksek Lisans Tezi, Çukurova Üniversitesi. Adana, Türkiye.

Goldratt, E. M. (1990). The Haystack Syndrome: Sifting Information Out of the Data Ocean. USA: North River Press.

Gupta, M. \& Andersen: (2018). Throughput/İnventory Dollar-Days: TOC-Based Measures for Supply Chain Collaboration. International Journal of Production Research, 56(13), 4659-4675. https://www.tandfonline.com/doi/pdf/10.1080/00207543.2018.1444805?needAccess=true Adresinden Alınd1

Hanqi, Fu. (2006). Constructing Decision Support System Based on Throughput Accounting of TOC. National Chiao Tung University, master's degree. Taiwan. https://hdl.handle.net/11296/2c82qv Adresinden Alındı

Hua, W. Ch. (2014). New Pricing Policy by Using TOC Throughput Accounting-A Study of Semiconductor Assembly Plant. National Chiao Tung University, Master's Degree. Taiwan. https://hdl.handle.net/11296/bnxk7p Adresinden Alındı

Huang, SH. P. (2013). Application of TOC Throughput Accounting in the Company to Formulate the Order Acceptance Strategy - The Case of Testing Industry. Mingxin University of Science and Technology, Master's Degree. Taiwan. https://hdl.handle.net/11296/e4xyht Adresinden Alınd1

Hutchinson, R. (2007). The Impact of Time-Based Accounting on Manufacturing Performance. Doctor of Philosophy degree. USA: Manufacturing Management \& Engineering / The University of Toledo.

ICAI. (2016). Strategic Cost Management - Decision Making / Final Paper: 15 - Study Notes. India: The Institute of Cost Accountants of India.

IMA. (1999). Statements on Management Accounting - Strategic Cost Management / Title: Theory of Constraints (TOC) Management System Fundamentals. Montvale, NJ, USA: The Institute of Management Accountants (IMA).

Kaygusuz: Y. (2011). Kısıtlar Teorisi ve Maliyet Hacim Kâr Analizi: Bir Çalışma Sayfası Modellemesi. Muhasebe ve Finansman Dergisi, 171-188.

Lin, Ch-Hs. \& Tasi, Ch-Hu. \& Li, Ro-Kw. \& Tsai, Sh-Ch. \& Lu, Mi-Je. \& Ho, Sh-Ch. (2013, April). An Implementation of Using Throughput Dollar-Day in IC Design Industry Outsourcing Management: a Case Study. International Journal of Academic Research in Business and Social Sciences, 3(4), 1-20. http://hrmars.com/admin/pics/1712.pdf Adresinden Alınd 1

Majerčák, P. \& Cisko: \& Majerčáková, E. (2013, September). The Impact of Theory of Constraints on The Management Accounting. The 7th International DaysofStatistics and Economics, 894-902.

Mokabel, I. (2016). Importance of Managerial Accounting for a Successful Lean Transformation: A practical study at a large aerospace OEM. Mechanical and Industrial Engineering - Degree of Master. Montreal, Quebec, Canada: Concordia University.

Myrelid, A. (2013). Manufacturing Related Management Accounting. Linköping Studies in Science and Technology / MA Thesis. Linköping, Sweden: Linköping University / Department of Management and Engineering.

Neely, A. \& Gregory, M. \& Platts, K. (2005). Performance Measurement System Design a Literature Review and Research Agenda. International Journal of Operations \& Production Management IJOPM, 25(12), 12281263.

Parkhi, Sh. \& Tamraparni, M. \& Punjabi, L. (2015). Throughput Accounting: An Overview and Framework. Int. J. Services and Operations Management, X(Y, xxxx), 1-20. 
Ricketts, J. A. (2007). Reaching The Goal: How Managers Improve a Services Business Using Goldratt's Theory of Constraints. USA: IBM Press.

Salafatinos, Ch. (1995). Integrating The Theory of Constraints and Activitybased Costing. Journal Of Cost Management, 9(3), 10-58.

Savcı, M. \& Balioğlu, İ. (2019). Kısıtlar Teorisine Göre İşletmelerin Performans Ölçümünde Süreç Katkı Muhasebesinin Rolü. Artvin International Congress On Social Sciences (AICOSS 19) (s. 190-196). Artvin Türkiye: AICOSS.

Scarlett, B. (2005). Management Accounting - Performance Evaluation / Managerial Level. UK: CIMA Official Study System / Elsevier Ltd.

Tanış, V. N. (1998). Yönetim Muhasebesi Açısından Kısıtlar Teorisi ve Süreç Muhasebesi. Çukurova Üniversitesi I.I.B.F. Dergisi, 8(3), 185-198.

Tüfekçi, B. \& Karaca: S. (2019). İşletmelerin Nakit Akış Profillerinin Analizi: Uluslararası Bir Karşılattırma. Sosyal Bilimler Araştırmaları Dergisi, 157-180.

Ünal, E. N. (2000). Kısıtlar Teorisi ve Yönetim Muhasebesi Açısından Değerlendirilmesi: Bir Sanayi Işsletmesinde Uygulama. Yüksek Lisans Tezi. Adana: Çukurova Üniversitesi, Sosyal Bilimler Enstitüsü.

Walker, W.T. (2002). Practical Application of Drum-Buffer-Rope to Synchronize A Two-Stage Supply Chain. Production and Inventory Management Journal, 3/4(43), 13-23.

Yao, Ch. Ch. (2011). Application of the Concept of TOC Throughput Accounting to Product Mix and Profit Maximum Decisions in IC Manufacturing Company. National Chiao Tung University, Master's Degree. Taiwan. https://hdl.handle.net/11296/j22xk4 Adresinden Alındı

Yurevich: A. \& Vasilevna, E. T. \& Anatolyevna: T. (2018). Developing Budgeting And Control İn Throughput Accounting System. Advances in Economics, Business and Management Research (61), 307-312. 